\title{
Definition of humidification circuit parameters for drip irrigation
}

\author{
Boris M. Kizyaev ${ }^{1}$, Victor I. Balabanov ${ }^{2}$, and Natalia B. Martynova ${ }^{2 *}$ \\ ${ }^{1}$ Russian Scientific Research Institute of Hydraulic Engineering and Melioration named after A.N. Kostyakov, 127550 Moscow, \\ Russian Federation \\ ${ }^{2}$ Department of Land Reclamation and Construction Machines, Russian State Agrarian University, Moscow Agricultural Academy \\ named after K.A. Timiryazev, 127550 Moscow, Russian Federation
}

\begin{abstract}
During recent years, there was a steady growth in the gross harvest of potatoes in Moscow region, production capacities for processing of agricultural crop have been also increasing. However, based on 2020 results, the yield is still highly dependent on weather conditions and, in particular, on the amount of precipitation during the growing period. Therefore, in order to obtain sustainable yields, it is necessary to maintain the optimal values of the water-air balance, that consider conduction of agromeliorative measures, including additional irrigation. The most economical is drip irrigation among the moisturizing activities. It allows to deliver irrigation water directly to the root zone. This will significantly reduce the cost of water and electricity; however, the maximum benefits of drip irrigation may be obtained by revise and calculation of the irrigation rates. Suggested irrigation rates do not take into account the elliptical shape of the humidification contour, which leads to overestimated rates for it. The method for calculating the irrigation rate proposed in the article, takes into account the shape of the humidification contour that enables to use irrigation water wisely.
\end{abstract}

\section{Introduction}

Moscow region is characterized by uneven precipitation not only in the spring-summer period but also during a year. There are non-precipitating days or even weeks happen after one-off rains when tens of millimeters of precipitation fall. During summer period, downpour is the most often type of rains [1]. It is distinct by the case when a significant part of the moisture does not have time to be absorbed into the soil and therefore goes to the surface runoff. In winter period, the thickness of snow cover fluctuates widely and there may be no snow cover at all that have been noticing over recent last years [2]. The amount of precipitation in high-water and low-water years can vary in 2 or even more (Fig. 1).

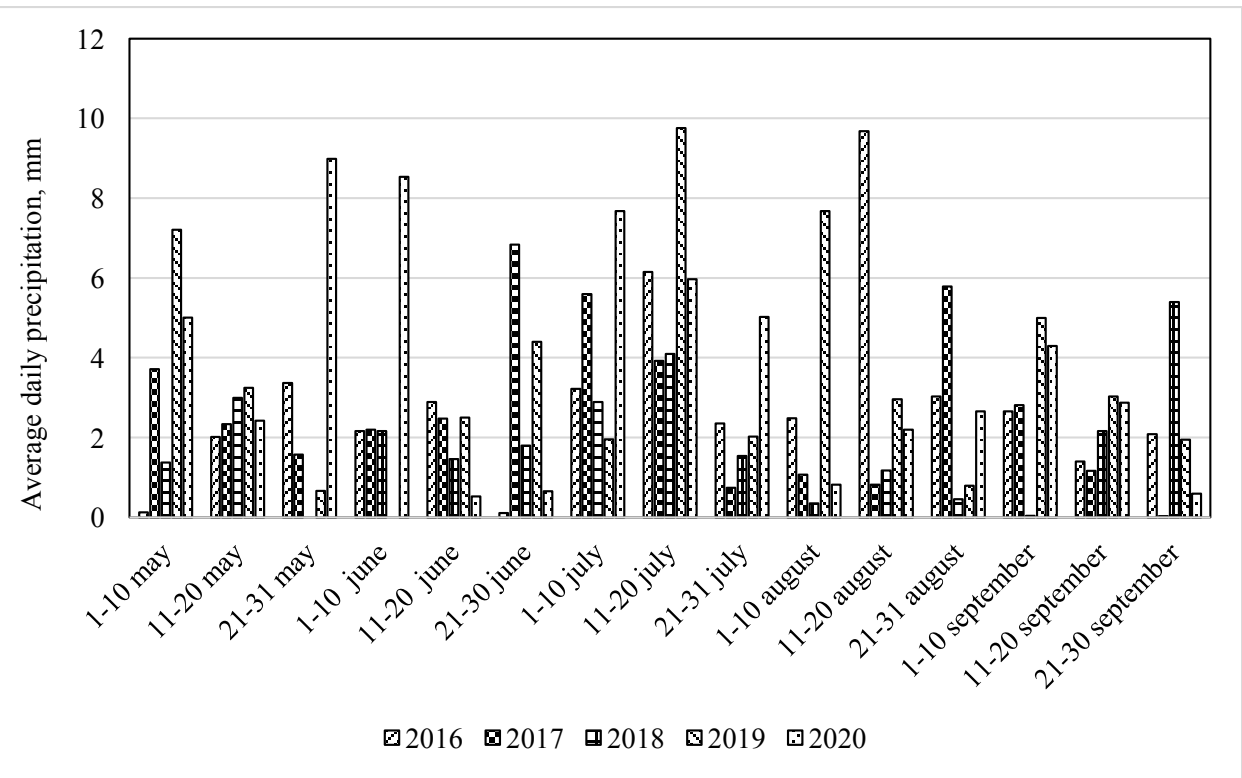

Fig. 1. Dynamics of the average daily precipitation during the growing season of potatoes

\footnotetext{
* Corresponding author: yourim2@,rambler.ru
} 
Such conditions do not allow to reach high yield level without appliance of agromeliorative measures [3]. In order to contribute for agriculture development and provide stable meal supply for population in 2014, the Government of Moscow Region commenced the State Program "Agriculture of Moscow Region", scheduled to continue until 2020. Implementation of this program, in particular subprogram number 2 named as "Development of land reclamation for agricultural purposes" made it possible to revitalize and return back for agricultural use more than 18 thousand hectares of retired lands by means of technical restoration works [4]. However, an emerging trend of growth in the gross harvest of potatoes, which peaked at 460 thousand tons in 2019, was changed by a decrease in yield from 32.37 to 24,87 tons in hectare in 2019 and 2020 respectively that caused to a loss of planned harvest in volume of 36 thousand tons (Table 1).

Table 1. The size of the cultivated area and the yield of potatoes in the Moscow region.

\begin{tabular}{|l|l|l|l|l|l|l|l|l|}
\hline Indicators & \multicolumn{2}{l|}{ Research period, years } \\
\cline { 2 - 11 } & 2013 & 2014 & 2015 & 2016 & 2017 & 2018 & 2019 & 2020 \\
\hline Sown area, thousand hectares & 14,1 & 13,2 & 14,6 & 13,7 & 12,9 & 12,7 & 13,7 & 13,5 \\
\hline Productivity, thousand tons & 210 & 306 & 392 & 360 & 330 & 318 & 460 & 289 \\
\hline
\end{tabular}

The reason was a heavy rainfall in early summer, and then a shortage in the middle and late part of the summer [5]. The harvested crop often did not meet quality standards, and the lost volumes had to be replaced by imported products. The region, which takes the 3rd place in Central Region in terms of gross harvest of potatoes, with a well-developed network of agro-processing enterprises, the total capacity of which allows processing up to 170 tons per year, should use the technical and scientific potential to reduce risks of crops shortage due to weather conditions [6].

\section{Means and Methods}

In order to obtain a guaranteed potatoes yield, the optimal water-air balance should be maintained during growing period. Among other agromeliorative measures, additional irrigation is required $[7,8]$. The advantage of drip irrigation is the delivery of irrigation water directly to the root inhabited area, while there are practically no losses for evaporation and filtration into the underlying soil layers, often accompanied by the washing out of nutrients from the root layer. Thanks to this method of water supply, excessive watering does not occur which usually leads to the formation of a dense crust on the soil surface. Drip irrigation practically allows to avoid moistening in the aisles, which significantly slows down the growth of weeds [9]. However, the share of drip irrigation among other methods of moistening remains low being a few percent of 4633 thousand hectares of irrigated land only in Russian Federation [10]. The rate of introduction of drip irrigation, which showed quite positive results 10 - 20 years ago, has slowed down significantly in recent years. One of the main advantages of drip irrigation is a significant water saving, which is not fully implemented due to increased irrigation requirements or rates $[11,12]$. The existing irrigation rates do not take into account the shape of the humidification contour, which is a truncated ellipse (Fig. 2).

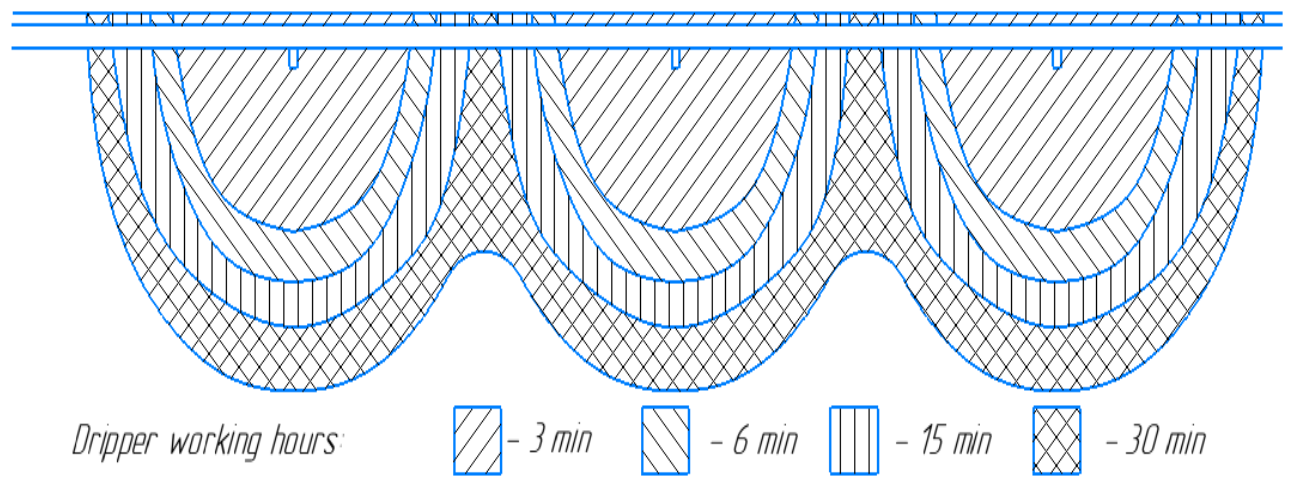

Fig. 2. Formation of the humidification contour during the operation of the dropper

In practice, irrigation rates are the same that used for water seeps in a continuous layer, as in continuous pouring, in some cases corrections are given for non-irrigated areas of row spacings, however, such calculation methods have lower accuracy. Most researchers tend to the semi-elliptical shape of the contour, which has some geometric features depending on the pore volume and the amount of clay particles in the soil $[13,14]$.

Being in the soil, water moves horizontally under the capillary forces, and in the vertical direction - under the action of capillary and gravitational forces. Therefore, the movement of water particles in the soil should be considered separately in the horizontal and vertical directions (Fig. 3). 


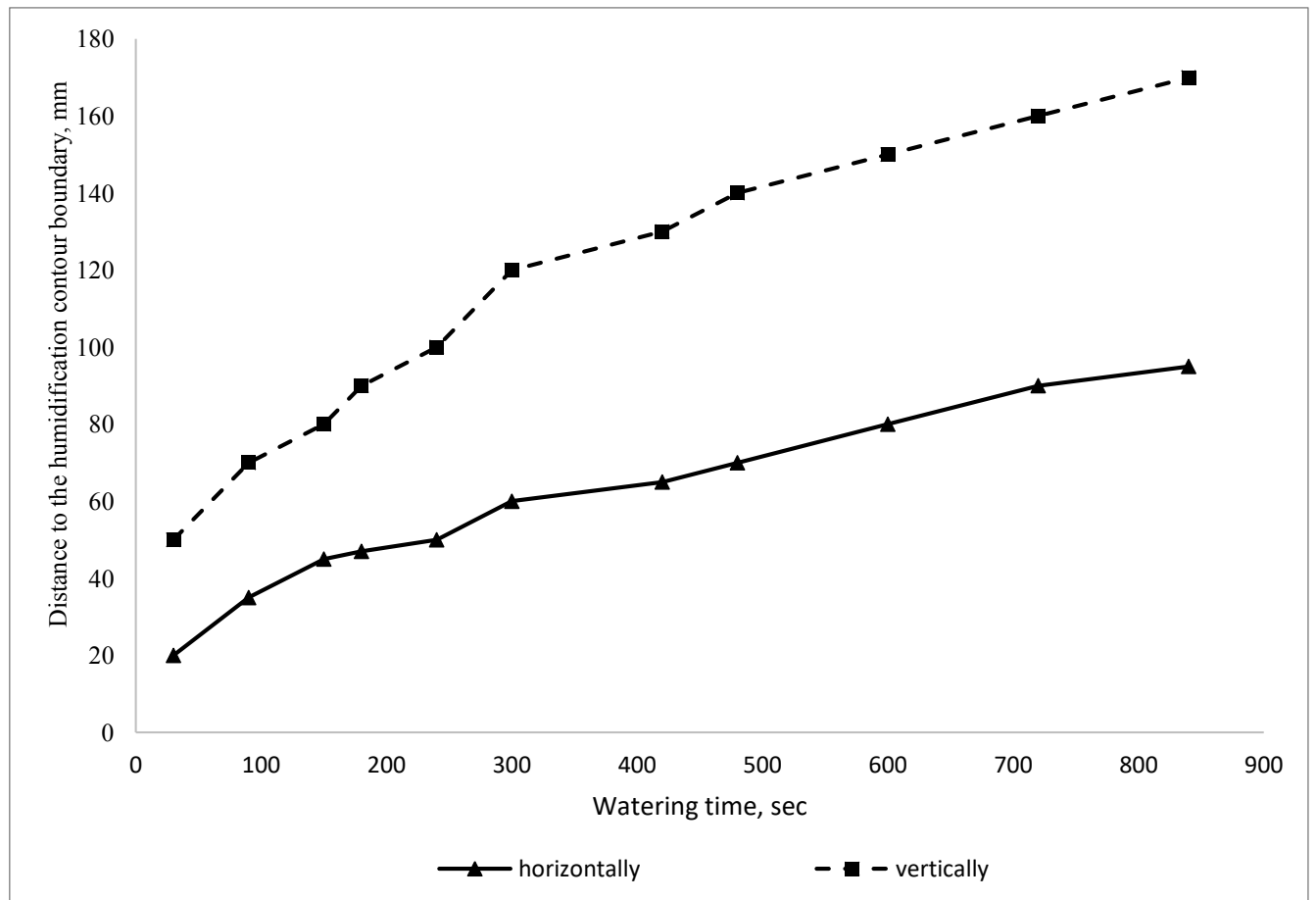

Fig. 3. Dynamics of the distribution of irrigation water in the soil in the horizontal and vertical directions

The vertical movement of moisture in an unsaturated medium is determined by [15]:

$$
\frac{\partial \mathrm{W}}{\partial \mathrm{t}}=\frac{\partial}{\partial \mathrm{z}}\left(\mathrm{D}(\mathrm{W}) \frac{\partial \mathrm{W}}{\partial \mathrm{z}}+A \frac{\partial^{2} \mathrm{~W}}{\partial \mathrm{t} \partial \mathrm{z}}\right)
$$

where: D (W) - coefficient of diffusivity of soil moisture; A - correction factor; W is the relative humidity of the soil; $\mathrm{t}$ - time, sec.

The vertical coordinate dividing the watered and non-watered zones is determined by the formula:

$$
\mathrm{z}=2 \mathrm{~A}^{-0,5} \sqrt{\mathrm{Dt}}
$$

The coefficient of diffusion of soil moisture is determined as the following [16]:

$$
D(W)=D_{0} \cdot e^{\beta\left(W-W_{0}\right)}
$$

where: $\beta$ is a parameter depending on soil and moisture; $\mathrm{D}_{0}$ - diffusivity coefficient at initial humidity $\mathrm{W}_{0}$.

The parameters included in this formula were investigated in various soil conditions, and can be described by the formula:

$$
\beta=\frac{1}{\mathrm{~W}_{1}-\mathrm{W}_{0}} \ln \left(\frac{3\left(\mathrm{~W}_{1}-W_{\mathrm{M}}\right)^{3,5}}{\mathrm{~W}_{1}^{2}\left(\mathrm{~W}_{0}-W_{\mathrm{M}}\right)^{3,5}\left(\frac{1}{\mathrm{~W}_{0}^{2}}+2 \frac{\mathrm{W}_{0}}{\mathrm{~W}_{1}^{3}}\right)}\right)
$$

The diffusivity coefficient at the initial moisture content for the given soil conditions can be determined by the formula [17]:

$$
\mathrm{D}_{0}(\mathrm{~W})=\frac{\mathrm{K}_{\Phi} \Psi_{\mathrm{M}} W_{\mathrm{M}}}{1-\left(\frac{W_{\mathrm{M}}}{\mathrm{W}_{1}}\right)^{3}}\left(\frac{\mathrm{W}_{0}-W_{\mathrm{M}}}{\mathrm{W}_{1}-W_{\mathrm{M}}}\right)^{3,5} \cdot\left(\frac{1}{\mathrm{~W}_{0}^{2}}+2 \frac{\mathrm{W}_{0}}{\mathrm{~W}_{1}^{3}}\right)
$$

where: $\Psi_{M}$ - value of soil moisture pressure at humidity level $\mathrm{Wm}$. 
To determine the capillary pressure, use the following formula to be used [18]:

where: $\mathrm{v}$ - empirical coefficient, for mineral soils $\mathrm{v}=2,7$.

$$
\Psi=-\mathrm{h}_{\mathrm{k}} \sqrt[3]{\frac{1}{\mathrm{v}} \ln \frac{\mathrm{W}-W_{\mathrm{M}}}{\mathrm{m}-W_{\mathrm{M}}}}
$$

The horizontal movement of soil moisture can be described by the equation $[19,20]$ :

$$
\frac{\partial \mathrm{W}}{\partial \mathrm{t}}=\frac{\partial}{\partial \mathrm{x}}\left(\mathrm{D}(\mathrm{W}) \frac{\partial \mathrm{W}}{\partial \mathrm{x}}\right)
$$

After transformations, we find the coordinate of the irrigation contour radius:

$$
x=\sqrt{\frac{2 t D_{0} e^{\beta\left(W-W_{0}\right)} \cdot \sqrt{A}}{\sqrt{A}-\beta\left(W-W_{0}\right) \sqrt{2 D_{0} e^{\beta\left(W-W_{0}\right)}}}}
$$

Knowing the radius of the irrigation contour in a given period of time, it is possible to determine the flow rate for the dropper and calculate the irrigation rate.

\section{Results and Discussion}

To determine the flow rate consumption for the dropper, taking into account the shape of the humidification contour of the truncated ellipse, we find:

$$
Q_{\text {тр }}=\frac{2 \cdot 3,6 \cdot 10^{-3} \pi z x^{2}\left(W_{1}-W_{0}\right)}{3 t}
$$

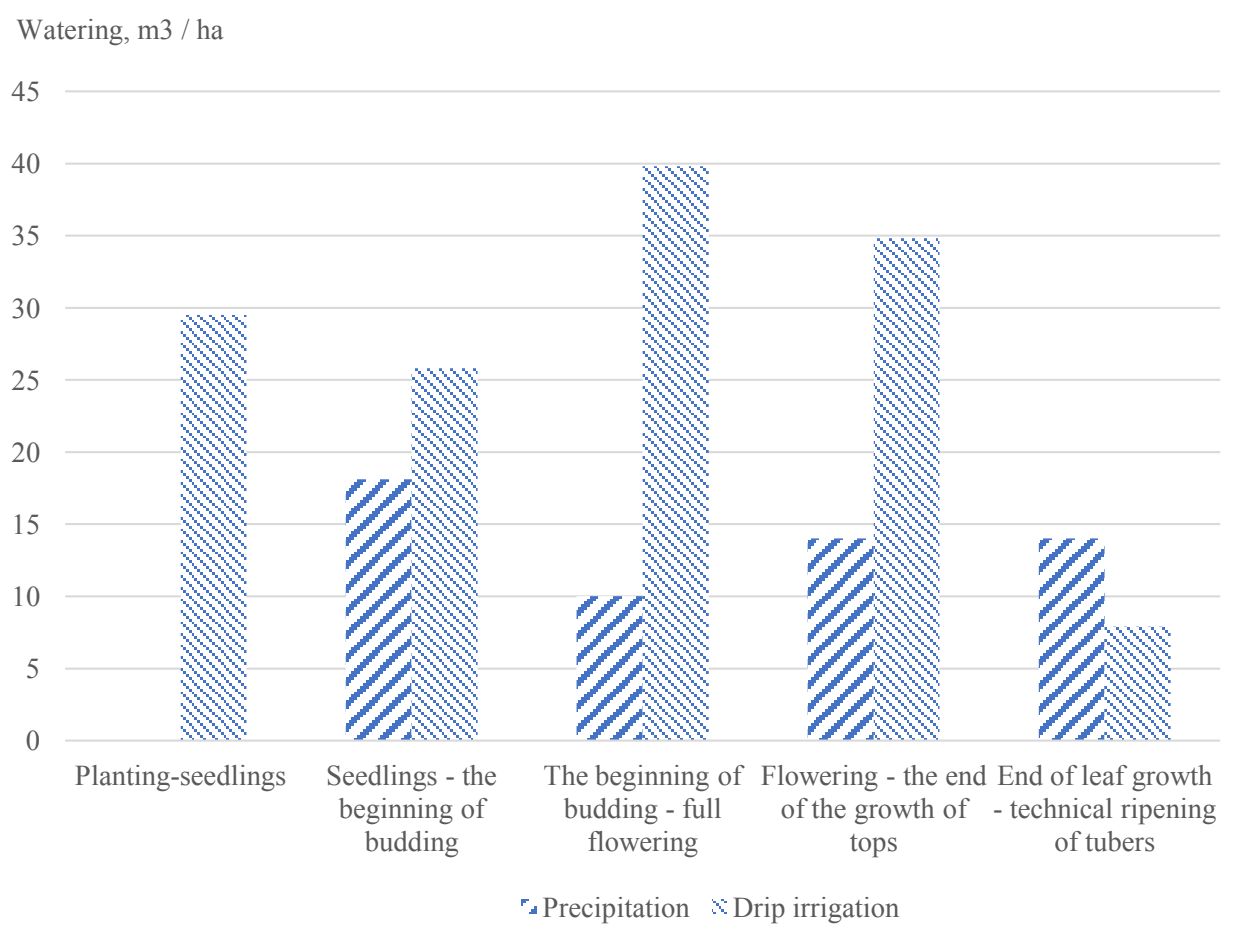

Fig. 4. Water consumption of potatoes at different stages of development

Next, a drip tape from the condition Qcap $\geq$ Qtr should be chosen. After analyzing the formula, from the model range, a tape with optimal parameters for a given crop (Table 2) to be chosen as well. 
Table 2. Drip tape parameters

\begin{tabular}{|l|l|}
\hline parameter & value \\
\hline drip flow rate, $1 / \mathrm{h}$ & 1,4 \\
\hline drip tape diameter, $\mathrm{mm}$ & 16 \\
\hline distance between droppers, $\mathrm{mm}$ & 300 \\
\hline
\end{tabular}

The numerical value of the irrigation rate can be calculated using the formula:

$$
m=\frac{10 \cdot Q_{\text {кап }} \cdot t}{3,6 \cdot l \cdot b}
$$

where: 1 - distance between droppers, $\mathrm{m}$; $\mathrm{b}$ - distance between adjacent ridges, $\mathrm{m}$.

Using the calculation methodology above, the irrigation water consumption was reduced by $12 \%$. In the process of research, it was taken into account that in the initial period of development, the plant has enough moisture reserves of the mother tuber and there is practically no need for additional moisture. During this period, the soil is sufficiently moistened after snowmelt. The need for additional irrigation arises during the period of foliage growth, reaching maximum values during the period of termination of foliage growth and flowering. Then water consumption decreases slightly. Therefore, the drip tape was laid in conjunction with the operation to form potato ridges.

In the process of further research, irrigation was carried out with the proposed irrigation rate when the pre-irrigation moisture threshold was reached with adjusting of the time between irrigations (Fig. 4).

\section{Conclusions}

Moscow region is characterized by uneven precipitation not only in the spring-summer period and also during a year. Therefore, in order to maintain the optimal values of the water-air balance of the plant during the growing season, it is necessary to carry out agromeliorative measures, including additional irrigation. The advantage of drip humidification is the delivery of water to the root space. Calculation of the irrigation rate taking into account the elliptical shape of the humidification contour that made it possible to reduce the irrigation water consumption by $12 \%$.

\section{Acknowledgments}

The article was prepared with the support of the Ministry of Education and Science of Russia within the framework of agreement No. 075-15-2021-032 dated March 23, 2021 on the provision of a grant in the form of a subsidy for the creation and development of an engineering center on the basis of an educational institution of higher education and (or) a scientific organization in within the framework of the federal project "Development of infrastructure for research and training" of the national project "Science and Universities".

\section{References}

1. N.N. Dubenok, D.A. Bolotin, A.A. Novikov, A.G. Bolotin, Bulletin of the Nizhnevolzhsky agro-university complex: science and higher professional education 51(3), 81 - 90 (2018)

2. O.A. Starovojtova, N.E. Shabanov, The Herald of the Moscow State Agricultural Engineering University named after V.P. Goryachkin 74(4), 34-40 (2016)

3. J. Reyes-Cabrera, L. Zotarelli, M.D. Dukes, D.L. Rowland, S.A. Sargent, Agricultural Water Management 169, 183-192 (2016)

4. N.B. Martynova, A.Yu. Korneev, The Herald of the Moscow State Agricultural Engineering University named after V.P. Goryachkin 84 (2), 18 - 22 (2018)

5. A.S. Shtahko, V.N. Shkura, Scientific journal of the Russian Research Institute of Melioration Problems 31(3), 39 -57 (2018)

6. S.M. Vasiljev, V.N. Shkura, A.S. Shtahko, Bulletin of the Nizhnevolzhsky agro-university complex: science and higher professional education 52(4), 316 - 323 (2018)

7. H.A. Abdulmazhidov, A.S. Matveyev, The Herald of the Moscow State Agricultural Engineering University named after V.P. Goryachkin 72(2), 40-46 (2016)

8. A.S. Ovchinnikov, A.A. Buber, Yu.P. Dobrachev, V.V. Borodychev, Bulletin of the Nizhnevolzhsky agrouniversity complex: science and higher professional education 54(4), 65-76, 2018

9. A.S. Ovchinnikov, V.S. Bocharnikov, M.P. Mesherjakov, O.V. Bocharnikova, Bulletin of the Nizhnevolzhsky agro-university complex: science and higher professional education 48(4), 10 - 16 (2017)

10. N.N. Dubenok, D.A. Bolotin, S.D. Fomin, A.G. Bolotin, Bulletin of the Nizhnevolzhsky agro-university complex: science and higher professional education 48(4), 22 - 29 (2017)

11. M.N. Makani, S.A. Sargent, L. Zotarelli, D.J. Huber, C.A. Sims, Scientia Horticulturae 197, 428-433 (2015) 
12. J. Reyes-Cabrera, L. Zotarelli, D.L. Rowland, M.D. Dukes, S.A. Sargent, American Journal of Potato Research 91(5), 504-516 (2015)

13. V.N. Krasnoshchekov, D.G. Olgarenko, Environmental Management 4, 51-57 (2016)

14. B.M. Kizjaev, N.B. Martinova, Irrigation and Reclamation 13(3), 62-65 (2018)

15. E.V. Zhalnin, The Herald of the Moscow State Agricultural Engineering University named after V.P. Goryachkin 82(6), 10-14 (2017)

16. N.K. Telov, H.A. Abdulmazhidov, The Herald of the Moscow State Agricultural Engineering University named after V.P. Goryachkin 91(3), 22-27 (2019)

17. L.V. Kireycheva, V.M. Yanshin, Melioration and water management 5, 31 - 35 (2019)

18. V.A. Shevchenko, V.P. Maksimenko, V.K. Gubin, L.V. Kudrjavtzeva, Bulletin of the Russian agricultural science 6, $84-86(2018)$

19. V.P. Maksimenko, V.A. Shevchenko, V.K. Gubin, Bulletin of the International academy of Agricultural Education 36, 82 - 85 (20170

20. G.I. Bondareva, Rural mashine operator 10, 22 - 23 (2020) 